Pacific Northwest National Laboratory

Operated by Battelle for the

U.S. Department of Energy

Under Contract DE-AC-05-76RL01830
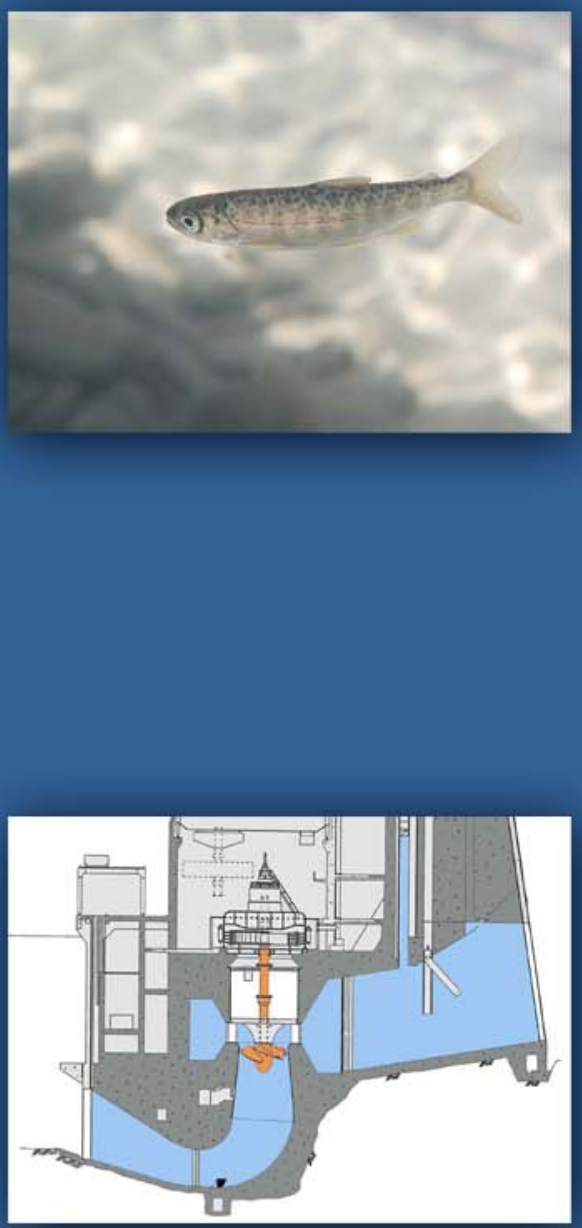

\section{Effect of Multiple Turbine Passage on Juvenile Snake River Salmonid Survival}

Final Report

September 2005
Wind and Hydropower Technologies

Bringing you a prosperous future where energy is clean, abundant, reliable, and affordable 


\title{
DISCLAIMER
}

This report was prepared as an account of work sponsored by an agency of the United States Government. Neither the United States Government nor any agency thereof, nor Battelle Memorial Institute, nor any of their employees, makes any warranty, express or implied, or assumes any legal liability or responsibility for the accuracy, completeness, or usefulness of any information, apparatus, product, or process disclosed, or represents that its use would not infringe privately owned rights. Reference herein to any specific commercial product, process, or service by trade name, trademark, manufacturer, or otherwise does not necessarily constitute or imply its endorsement, recommendation, or favoring by the United States Government or any agency thereof, or Battelle Memorial Institute. The views and opinions of authors expressed herein do not necessarily state or reflect those of the United States Government or any agency thereof.

\author{
PACIFIC NORTHWEST NATIONAL LABORATORY \\ operated by \\ BATTELLE \\ for the \\ UNITED STATES DEPARTMENT OF ENERGY \\ under Contract DE-AC05-76RL01830
}

Printed in the United States of America

\author{
Available to DOE and DOE contactors from the \\ Office of Scientific and Technical Information, \\ P.O. Box 62, Oak Ridge, TN 37831-0062; \\ ph: (865) 576-8401 \\ fax: (865) 576-5728 \\ email: reports@adonis.osti.gov
}

\begin{abstract}
Available to the public from the National Technical Information Service, U.S. Department of Commerce, 5285 Port Royal Rd., Springfield, VA 22161 ph: (800) 553-6847$$
\text { fax: (703) 605-6900 }
$$

email: orders@ntis.fedworld.gov

online ordering: http://www.ntis.gov/ordering.htm
\end{abstract}




\title{
Effect of Multiple Turbine Passage on Juvenile Snake River Salmonid Survival
}

\author{
K. D. Ham \\ J. J. Anderson \\ J. A. Vucelick
}

September 2005

Prepared for

the U.S. Department of Energy

under Contract DE-AC05-76RL01830

Pacific Northwest National Laboratory

Richland, Washington 99352 


\section{Executive Summary}

Juvenile salmonids originating in the Snake River upstream of Lower Granite Dam must pass up to eight hydroelectric projects during their downstream migration to the Pacific Ocean. Fish may pass a project through a turbine or a spillbay or be screened into a bypass system that either collects fish into a barge or releases them downstream of the project. Previous reviews of studies of downstream passage for salmon at hydroelectric projects in the Columbia River basin found higher mean mortality at turbines than for spillways or bypass systems. The potential mechanisms of mortality during turbine passage may include pressure changes, cavitation, shear, turbulence, strike, or grinding. Observing those mechanisms is challenging in the field, but laboratory studies have demonstrated that a single exposure to shear or pressure changes similar to turbine passage conditions can result in injury for some individuals. Because fish pass several dams along their migration, individuals experience a series of passage events. If estimates of surviving the passage of a single project are applied to each passage event, then the underlying assumption is that the mortality at each project is independent of previous exposure. If individuals approaching a project were already sub-lethally stressed, higher than expected mortality rates might occur upon subsequent passage events. Our hypothesis is that fish passing more than one turbine will experience a greater than expected rate of mortality. Because measuring an incremental increase in mortality would be challenging in the field, we developed an approach to first assess whether such an increment has any potential to influence a fish population. This approach identified populations at risk and will help design laboratory or field experiments to address those risks.

In our study, we used a spreadsheet model of juvenile salmonid passage and survival in the Snake and Columbia River systems to simulate passage-route histories across a range of conditions for several runs and to assess the risk of passing multiple turbines. The Simulated Passage model (SIMPAS) was developed by the National Marine Fisheries Service to simulate fish passage proportions through turbines and other routes along with route-specific survivals as calibrated by research results and regional consensus. The model was run under current system operational guidelines for some representative flow years to evaluate what conditions lead to the greatest risk of passing multiple turbines. The model was modified to simulate a hypothetical increase in mortality as a result of passing multiple turbines. This multiple turbine effect (MTE) was simulated at various levels, from a small increase in mortality to the extreme case of complete mortality upon passing more than one turbine.

The proportion of fish passing multiple turbines in a simulation varied due to species differences and distribution of flow among passage routes, and in response to management options such as the juvenile fish transportation program. Even at the most extreme levels of MTE simulated, the number of successful downstream migrant juvenile spring Chinook salmon (Oncorhynchus tshawytscha) and steelhead (O. mykiss) declined less than $8 \%$ during scenarios with transport. The number of juvenile fall Chinook salmon (O. tshawytscha) declined by $14 \%$ and $17 \%$, respectively, in low and average flow years with transport. An MTE of 59.0\% in a low-flow year or $44.5 \%$ in a high-flow year was required to reduce the number of successful downstream migrant juvenile fall Chinook salmon arriving downstream of Bonneville Dam by $10 \%$. For all runs and flow years, fewer juvenile salmon were predicted to arrive downstream of Bonneville Dam for scenarios where transport was turned off. 
By approaching the problem first with a simulation model, it was possible to determine that fall Chinook salmon in low and average flow years had the greatest potential for an MTE to reduce the number of juveniles arriving downstream of Bonneville Dam by at least 10\%. Modeling also predicted that a relatively large MTE would be required to reduce the number of migrants by $10 \%$. Because the MTE required to notably impact fall Chinook salmon is predicted to be large, a field experiment to detect whether it exists appears feasible. An experiment designed to detect impacts smaller than the threshold level could provide a statistically rigorous demonstration that the effect is too small to have an impact on the population. Conversely, the same experiment should easily detect an impact if it exceeded the threshold level. 


\section{Acknowledgments}

We especially wish to thank the U.S. Department of Energy Office of Energy Efficiency and Renewable Energy Wind and Hydropower Technologies Program for supporting this work.

Many people contributed to the success of this project. Gary Fredricks of NOAA Fisheries provided the SIMPAS model. Within the Pacific Northwest National Laboratory (PNNL), we much appreciate Dennis Dauble's involvement and oversight, as well as reviews provided by Andrea Currie and Russell Moursund. Thanks also to Duane Neitzel and Yetta Jager for helpful technical review comments. 


\section{Contents}

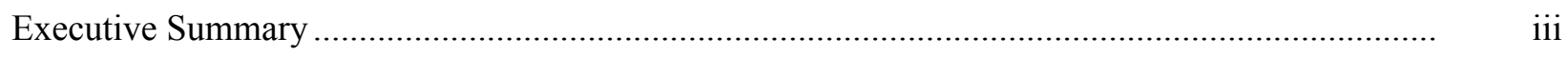

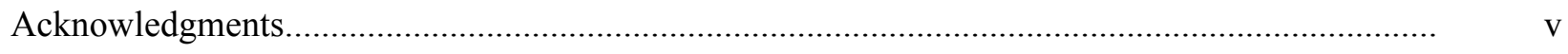

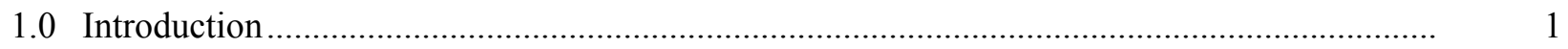

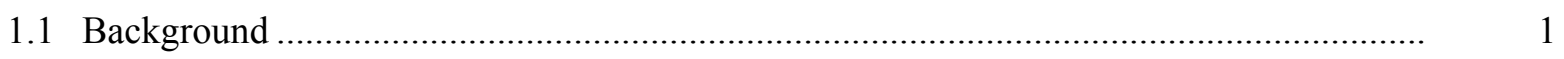

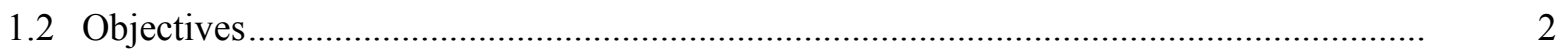

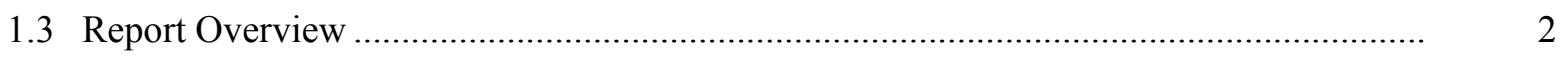

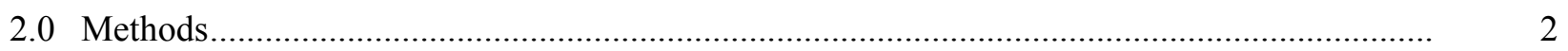

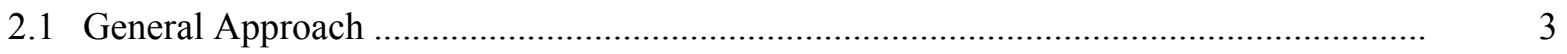

2.2 Modeling Fish Passage Routing and Survival.......................................................... 5

2.2.1 Differences Among Runs.............................................................................. 5

2.2.2 Flow Year Effects ...................................................................................... 5

2.2.3 Juvenile Fish Transportation Program ............................................................... 6

2.3 Simulating a Multiple Turbine Effect …................................................................. 6

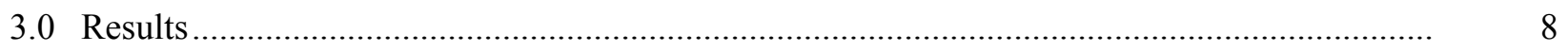

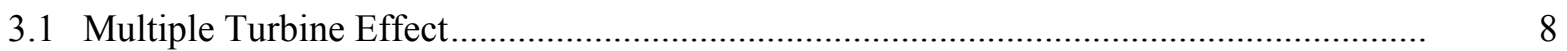

3.1.1 Maximum Simulated Multiple Turbine Effect …............................................... 8

3.1.2 What Level of Multiple Turbine Effect Is High Enough to Affect a Population?... 10

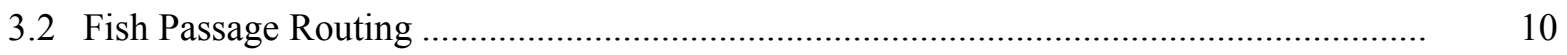

3.2.1 Differences Among Runs................................................................................ 11

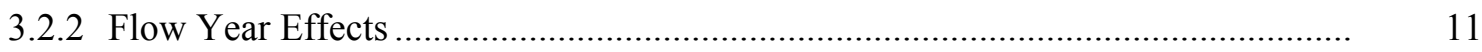

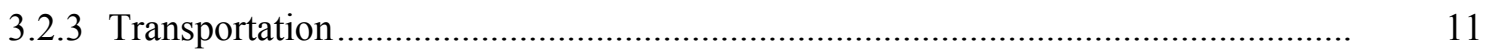

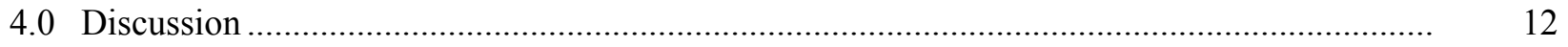

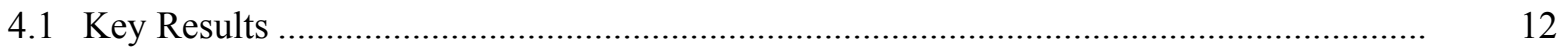

4.1.1 Managing the System to Reduce Turbine Passage .............................................. 12

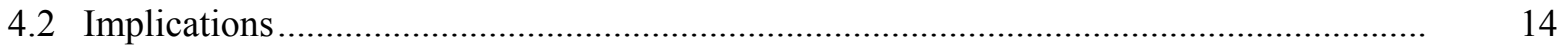

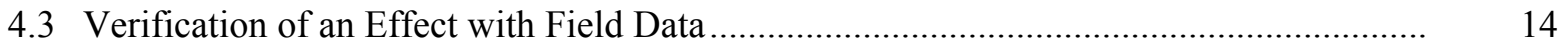

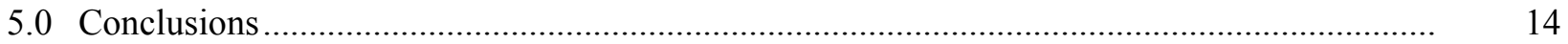

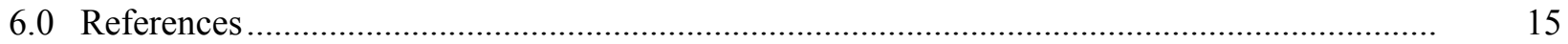




\section{Figures}

1.1 Dams on the Migration Route of Upper Snake River Stocks of Salmon and Steelhead........... 1

2.1 Simplified Flow Diagram of SIMPAS Model.......................................................................

2.2 Application of Multiple Turbine Effect to Survival as a Function of Fish Passage Routing..... 7

3.1 Proportion of Fish Passing Multiple Turbines in an Average Flow Year ................................ 9

3.2 Relative Survivals for Fall Chinook Salmon Versus Simulated Multiple Turbine Effect with and Without Transport During a Low-Flow Year........................................................ 10

3.3 Percentage of Steelhead Entering Lower Granite Pool Surviving at Each Hydropower Project in the River and in the Transport System Under Average Flows ................................ 12

4.1 System Survivals of Steelhead with or Without a Multiple Turbine Effect in an Average

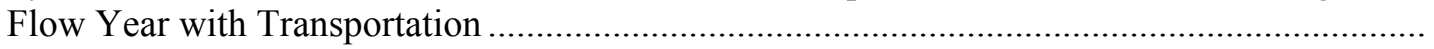

\section{Tables}

2.1 Scenarios of Run, Flow Year, and Transport Simulated Using the SIMPAS Model............... 5

2.2 Snake and Columbia River Mean Flows for Simulated Flow Years ...................................... 6

3.1 Relative Performance with Multiple Turbine Effect Set to $100 \%$........................................ 8

3.2 Percentage of Fish Passing One or More Turbines by Run, Flow Year, and Transport ........... 9

3.3 Multiple Turbine Effect Level at Which System Survival Is Decreased by $10 \% \ldots \ldots \ldots \ldots \ldots \ldots \ldots . . . . . . . .10$ 


\subsection{Introduction}

Juvenile salmon and steelhead from runs that spawn in the Snake River and its tributaries may pass as many as eight hydropower projects on their way to the Pacific Ocean (Figure 1.1). These juvenile migrants must reach the ocean and return to spawn in sufficient numbers to ensure the continuing health and persistence of the population. Operations are selected at hydropower projects to encourage juvenile migrants to pass via routes with high survival rates.

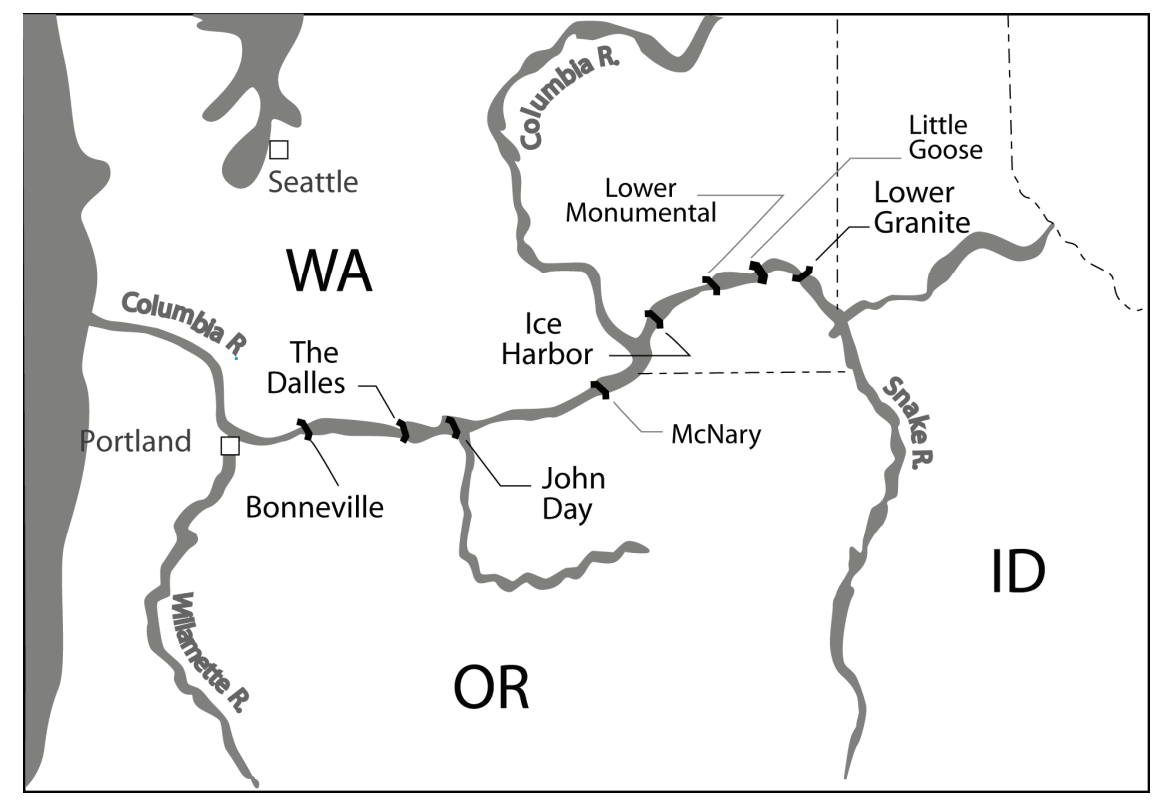

Figure 1.1. Dams on the Migration Route of Upper Snake River Stocks of Salmon and Steelhead (Source: U.S. Army Corps of Engineers)

\subsection{Background}

Migrating Snake River juvenile salmonids must successfully pass eight hydropower projects if they are to return as spawning adults. The survival rate of juvenile salmonids passing through Kaplan turbines of Snake and Columbia River hydroelectric dams is typically lower ( $90 \%$ of controls released downstream) than that of those passing the spillway or bypass system ( $\sim 98 \%$ of controls released downstream) of those dams (Schoeneman and Junge 1954; Schoeneman et al. 1961; Whitney et al. 1997; Coutant and Whitney 2000). To achieve sufficient juvenile survival rates, fish passage plans strive to decrease turbine passage by spilling water over the spillway and by collecting fish in bypass systems and transporting (barging or trucking) them downstream past the remaining dams. Although a smaller fraction of fish pass turbines, their survival is still important to the success of the run. Laboratory investigations of shear and pressure (e.g., Muir 1959; Groves 1972; Neitzel et al. 2004; Becker et al. 2003; Deng et al. 2005) have shown that conditions experienced in the turbine environment can impose stress on juvenile salmonids. If turbine passage imposes sub-lethal stress on surviving individuals, it may lead to a decreased ability to survive additional stressors (Mesa 1994; Čada 2001; Budy et al. 2002).

Does the stress of passing a single turbine influence the survival rate of individuals passing additional turbines? The studies mentioned above suggest that fish surviving a single turbine passage may be 
stressed, but it is difficult to measure whether survival rates are altered downstream. Field studies have estimated survival rates for a single turbine passage, but it is difficult to follow individuals past multiple hydropower projects. Only a fraction of tagged individuals pass turbines, and the difficulty in recapturing (detecting) those tags downstream means that a prohibitive number of tags would be required to achieve sufficient statistical power to detect an effect. Laboratory simulation of multiple turbine passage events is possible, but it would be impossible to test all possible passage histories. Rather than tackle the entire problem in a field or laboratory situation, we chose to employ a simulation model to identify areas of interest and opportunities for study in the laboratory or field.

This report describes a study conducted by Pacific Northwest National Laboratory to identify populations of migrating juvenile salmonids with a potential to be influenced by repeated exposure to turbine passage conditions. This project is part of a research program supported by the U.S. Department of Energy Wind/Hydropower Program, a goal of which is to increase hydropower generation and capacity while enhancing environmental performance.

\subsection{Objectives}

Our primary objective was to determine whether the incremental effects of multiple turbine passage during downstream migration have a potential to influence populations of salmonids. If such a potential is found to exist, a secondary objective will be to determine what level of effect of passing multiple turbines would be required to decrease the number of successful migrants in populations at risk by $10 \%$. This information will help identify where future laboratory or field studies are feasible and where the findings would have the greatest potential to address dam survival and thus benefit fish and power generation.

\subsection{Report Overview}

Chapter 2 provides a description of the methods used in our assessment of the potential for multiple turbine effects to affect fish populations. Chapter 3 presents the results of our assessment. Chapter 4 is a discussion of the findings. Our conclusions are presented in Chapter 5, followed by the references in Chapter 6.

\subsection{Methods}

This study sought to determine whether an incremental effect of multiple turbine passage during downstream migration has the potential to decrease the number of juveniles arriving downstream. Two critical pieces of information determine whether a population is likely to be influenced: 1) the proportion of juvenile migrants that passed more than one turbine and 2) the incremental change in survival resulting from multiple turbine passage relative to accepted single turbine passage survival rates. The approach we chose was to simulate passage and survival of juvenile salmonids migrating down the Snake and Columbia Rivers. We applied the worst multiple turbine effect possible $(0 \%$ survival for fish passing a second turbine) to identify combinations of run, flow level, and transport where there was a potential for a multiple turbine effect (MTE) to reduce the number of juveniles arriving downstream of Bonneville Dam 
by at least $10 \%$. For those populations, we ran the model in an iterative fashion to determine a multiple turbine effect (MTE-10\%) that resulted in a 10\% reduction in the number of outmigrants. We propose to use this MTE-10\% threshold to evaluate where field or laboratory studies are feasible and as a reference for comparison to the results of those studies.

\subsection{General Approach}

The sequence of passage routes for an individual fish was called its passage-route history. There are thousands of possible passage-route histories for fish migrating from the middle Snake River to the Pacific Ocean. The Columbia River hydropower system posed a challenge to understanding how fish populations interact with the system. For example, when only three potential pathways (spill, turbine, and bypass) at each of eight dams on the Snake and lower Columbia rivers were included, $3^{8}$ or 6561 passageroute histories were possible, each with its own sequence of exposure to turbine passage routes. Focusing on only whether or not the fish passed through a turbine resulted in 256 passage-route histories, 247 of which included exposure to multiple turbines.

The approach to begin addressing the range of turbine passage scenarios was to use a computer simulation of fish passage and survivals through the hydrosystem. We used the Simulated Passage (SIMPAS) model developed by the National Marine Fisheries Service (NMFS 2000). On the basis of field studies and regional consensus, this model routes individuals through the various passage routes available using simple curves that relate proportion of fish passing a route with the relative amount of flow through each route or the efficiency of screens in diverting fish into bypass systems (Figure 2.1). The model applies route- and dam-specific survival rates to each passage event. The model output of interest was the number of individuals that survived to exit the hydrosystem downstream of Bonneville Dam.

For this study, it was necessary to simulate both the total number of individuals surviving to exit the hydrosystem and to know passage routes of individuals at each project. Accordingly, the SIMPAS model was modified to track passage-route histories and to apply an incremental decrease in mortality for multiple turbine passage. These two capabilities allowed the influence of an MTE to be estimated.

To simplify passage histories, all forms of spill, such as spillways, sluiceways, and surface bypass routes, were combined into an inclusive spill category. The turbine passage route was available at all dams. All but The Dalles Dam had fish guidance screens that guided a portion of fish entering the turbine intake into a juvenile bypass system. Fish entering the bypass system were returned to the river or collected for transport in barges, depending upon which scenario was being simulated. Simulated fish passing a dam can pass through spill, turbine, or bypass. Those entering the bypass may be returned to the river or transported. Transportation was possible at only Lower Granite, Little Goose, and Lower Monumental dams on the Snake River and at McNary Dam on the Columbia River. All transported fish were released downstream of Bonneville Dam, the most downstream dam in the system. For our study, the important aspect of a passage-route history was how many times that individual passed through a turbine route. 


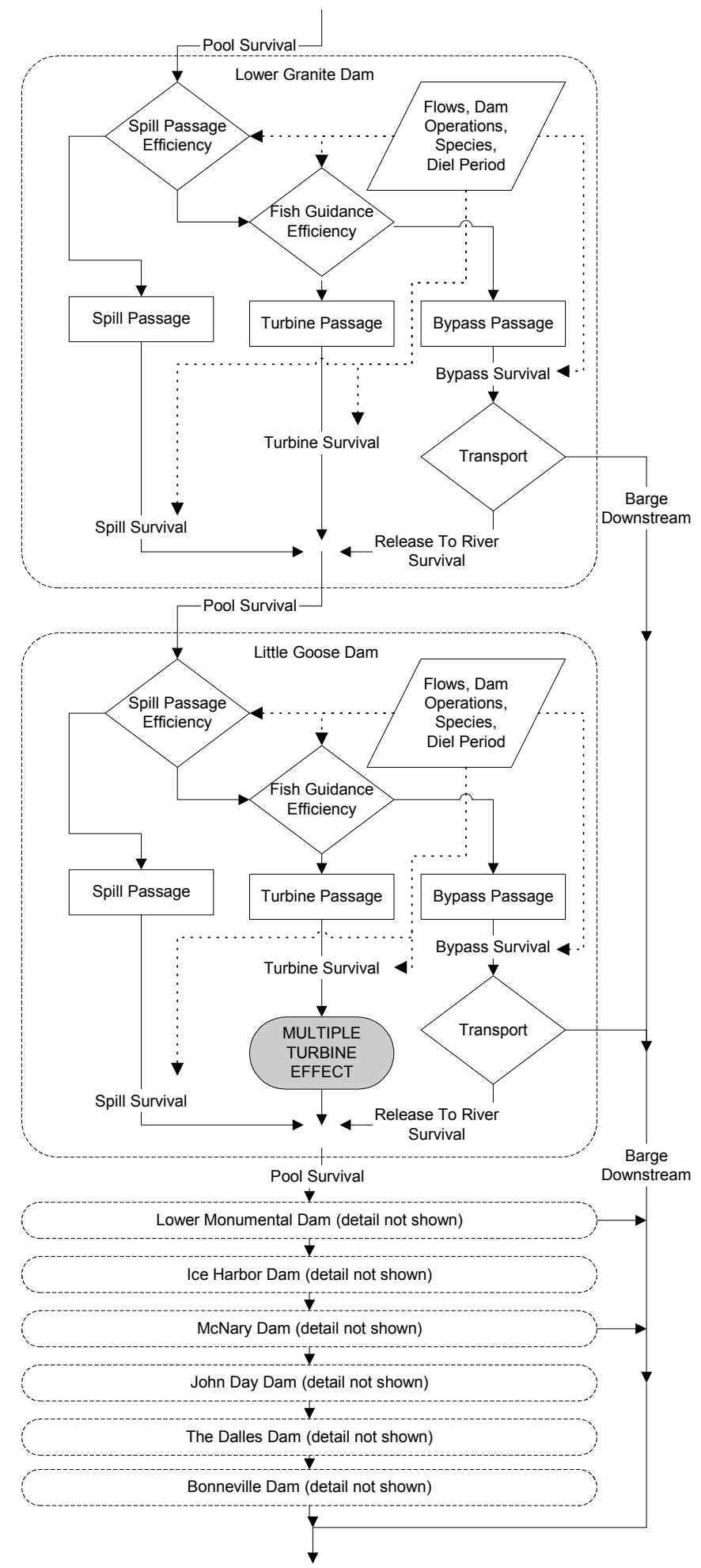

Figure 2.1. Simplified Flow Diagram of SIMPAS Model 


\subsection{Modeling Fish Passage Routing and Survival}

The SIMPAS model enabled fish routing and survival probabilities to be tracked for three populations across three flow levels and with the transportation system (barging) on or off. The values of parameters that determine fish routing and survival in the SIMPAS model were set to match the findings of studies and by regional consensus. Those values were not modified for this study, with the exception of imposing an incremental decrease in survival upon passing more than one turbine. Additional modifications to the SIMPAS model for this study allowed passage-route histories to be tracked through the entire system of eight dams and provided outputs required to analyze passage-route histories.

\subsubsection{Differences Among Runs}

The proportion of fish passing turbines, spill, or bypass differed among runs. For example, fish guidance screens are less efficient at diverting fall Chinook salmon away from turbine passage than for spring Chinook salmon (Oncorhynchus tshawytscha) or steelhead (Oncorhynchus mykiss) (Ferguson et al. 2004). As a result, more fall Chinook salmon (Oncorhynchus tshawytscha) pass through turbines under equivalent operational conditions. Another difference among runs is migration timing. Juvenile steelhead and spring Chinook salmon migrate downstream in the spring, whereas fall Chinook salmon migrate in the summer. Summer flows are lower, and the hydrosystem is managed differently to address factors such as temperature, water quality, predation risk, metabolic rate, and others that may influence fish survival during that portion of the migration time. Passage routing for fish migrating in the summer in an average year is often similar to that of fish migrating in spring of a low-flow year, which in recent years has meant foregoing spill to maximize the collection of fish for barging downstream past the dams. The SIMPAS model included data from several recent flow years, and one each was chosen to represent average-, high-, and low-flow years in simulations (low $=2001\left[3^{\text {rd }}\right.$ lowest flow volume for January through July period among 45 years from 1961-2005]; average $=1995$ [27 $7^{\text {th }}$ lowest $]$; high $=1997$ [highest]). Table 2.1 lists the combinations of flow year, run, and transportation system status that were simulated for this study.

Table 2.1. Scenarios of Run, Flow Year, and Transport Simulated Using the SIMPAS Model

\begin{tabular}{||c|c|c|c|c||}
\hline \multicolumn{2}{|c|}{} & \multicolumn{3}{c||}{ Run } \\
\hline \multirow{3}{*}{ Transport } & Flow Year & Steelhead & $\begin{array}{c}\text { Spring Chinook } \\
\text { Salmon }\end{array}$ & $\begin{array}{c}\text { Fall Chinook } \\
\text { Salmon }\end{array}$ \\
\hline \hline \multirow{3}{*}{ On } & Low & $\mathrm{X}$ & $\mathrm{X}$ & $\mathrm{X}$ \\
\cline { 2 - 5 } & Average & $\mathrm{X}$ & $\mathrm{X}$ & $\mathrm{X}$ \\
\cline { 2 - 5 } & $\mathrm{High}$ & $\mathrm{X}$ & $\mathrm{X}$ & $\mathrm{X}$ \\
\hline \multirow{2}{*}{ Off } & Low & $\mathrm{X}$ & $\mathrm{X}$ & $\mathrm{X}$ \\
\cline { 2 - 5 } & Average & $\mathrm{X}$ & $\mathrm{X}$ & $\mathrm{X}$ \\
\cline { 2 - 5 } & High & $\mathrm{X}$ & $\mathrm{X}$ & $\mathrm{X}$ \\
\hline
\end{tabular}

\subsubsection{Flow Year Effects}

Flow years change the amount of water available to apportion among routes, and also may trigger a change in the management of the river (Williams and Matthews 1995). The current fish passage plan 
(USACE 2005) states that in years when the seasonal average Snake River flow at Lower Granite is expected to be less than $70 \mathrm{kcfs}$, maximization of transportation will occur from the date the juvenile bypass systems begin operation. This means that water is not spilled, and all fish collected in the juvenile bypass systems at those projects where transport is an option are barged or trucked downstream of Bonneville Dam. At average flow levels in the spring, water is spilled at many of the collection dams, reducing the proportion of fish that are collected and transported. In summer, average flows are low, and maximum transport is the standard operation. At high-flow levels, the amount of spill may be constrained by powerhouse capacity or the desire to avoid exceeding dissolved gas limits. As a result, there is less flexibility to manage the routing of fish by altering the routing of water. Table 2.2 illustrates the Snake and Columbia River mean flows used in simulations by flow year and season.

Table 2.2. Snake and Columbia River Mean Flows for Simulated Flow Years

\begin{tabular}{||c|c|c|c|c|c||}
\hline \multicolumn{2}{|c|}{} & \multicolumn{2}{c|}{$\begin{array}{c}\text { Snake River Mean Flow } \\
(\mathrm{kcfs})\end{array}$} & \multicolumn{2}{c||}{$\begin{array}{c}\text { Columbia River Mean Flow } \\
(\mathrm{kcfs})\end{array}$} \\
\hline Calendar Year & Relative Flow & Spring & Summer & Spring & Summer \\
\hline \hline 2001 & Low & 48 & 26 & 122 & 88 \\
\hline 1995 & Average & 101 & 55 & 253 & 165 \\
\hline 1997 & High & 162 & 66 & 463 & 237 \\
\hline
\end{tabular}

\subsubsection{Juvenile Fish Transportation Program}

The juvenile fish transportation program collects fish that are guided into bypass systems at four dams in the Snake and Columbia Rivers and loads them into barges or, rarely, trucks. The dams at which the collection facilities are located are Lower Granite (Snake River Mile (SRM) 107.5), Little Goose (SRM 70.3), Lower Monumental (SRM 41.6), and McNary (Columbia River Mile 292.0). Fish collected at these dams are transported downstream past the remaining dams and returned to the river downstream of Bonneville Dam, the most downstream dam in the system. Once in the transportation system, the fish do not encounter additional turbines and, therefore, will not accrue any additional effects of passing turbines. Transportation can be turned on or off in the simulation model, thus allowing its influence on the potential for impacts from multiple turbine passage to be examined. Turning off transportation in a simulation differs from what is likely to appear in a comprehensive fish passage plan in that it occurs without adjusting other aspects of the system, such as increasing spill, to offset the lack of transportation. The simulations in this study simply returned fish to the river when transportation was turned off, but the remaining operational options remained unchanged. Turning off transportation in this way represented a worst-case scenario that helped identify the contribution of the transport system in limiting turbine passage, but it should not be considered a fully developed management option.

\subsection{Simulating a Multiple Turbine Effect}

The SIMPAS model simulates fish passage, and modifications allowed it to track whether or not a fish has previously passed through a turbine. For this study, that model was modified to simulate an effect of passing multiple turbines by imposing a decrease in survival rate beyond the expected survival rate for turbine passage for fish passing a second or higher turbine in its passage-route history. An individual that had previously passed a turbine would then be subject to a lower survival rate through a 
turbine than would a fish that had not previously passed a turbine (Figure 2.2). This simple definition of an MTE does not capture all subtleties of cumulative effects through the system, but it was sufficient for identifying where there was a potential for impact.

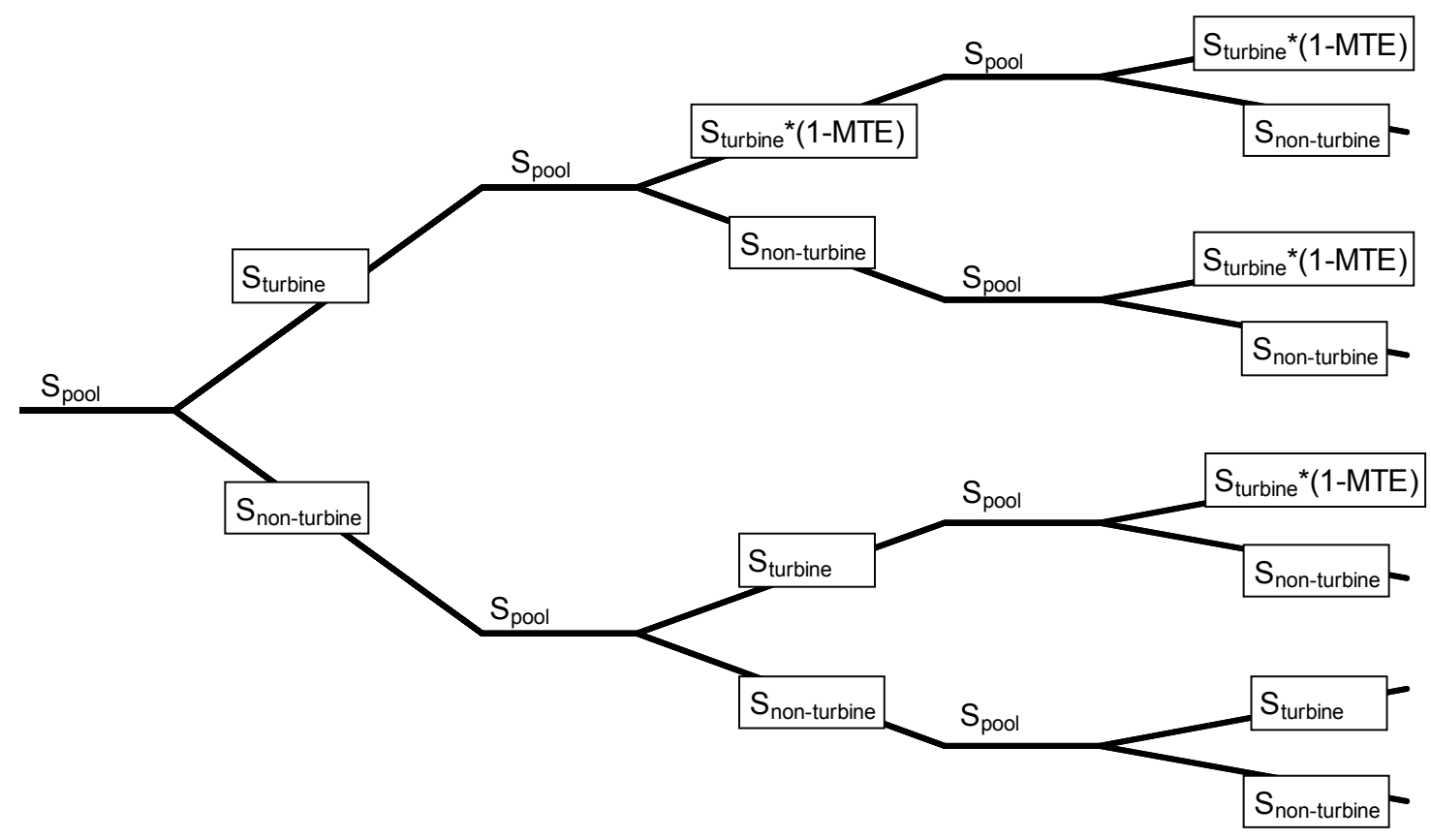

Figure 2.2. Application of Multiple Turbine Effect to Survival as a Function of Fish Passage Routing

An example of a group of fish that passed a turbine at Lower Granite Dam (LGR), spill at Little Goose Dam (LGS), turbine at Lower Monumental Dam (LMN), bypass at Ice Harbor Dam (IHR), and was barged from McNary Dam (MCN) is illustrated in Equation (2.1).

$$
S_{\text {pool }_{L G R}} S_{\text {turbine }_{L G R}} S_{\text {pool }_{L G S}} S_{\text {spill }_{L G S}} S_{\text {pool }_{L M N}} S_{\text {turbin }_{L M N}}(1-M T E) S_{\text {pool }_{\text {HRR }}} S_{\text {bypass }_{\text {IHR }}} S_{\text {pool }_{M C N}} S_{\text {barge }_{M C N}}
$$

where

$S_{\mathrm{ij}}$ is survival through the ith route type at the jth project, and

MTE is the multiple turbine effect.

This example illustrates that MTE decreases survival only for a second or subsequent turbine passage but does not apply to situations in which the group passes any other route type.

The magnitude of an MTE is not known, so the range from no effect to $100 \%$ decrease in survival must be considered. Setting MTE to the maximum level helps identify where there was a potential to reduce the number of individuals surviving the downstream migration. A maximum MTE level meant that no fish survived after they passed a second turbine. If a maximum MTE resulted in less than a $10 \%$ decrease in population survival for a specific combination of run, flow, and management option, then that combination was screened out, and further investigation focused on those combinations with a greater risk of impact. The value of $10 \%$ was a convenient value for determining which runs were at greater risk, but we do not wish to suggest that anything less than or equal to that value is of no consequence to a run. 
Once populations having a potential for impact were identified, we quantified the magnitude of MTE required to generate a $10 \%$ impact. This was accomplished by running the model in an iterative fashion to determine an MTE that resulted in a $10 \%$ reduction in the number of outmigrants, or MTE-10\%. We propose to use this MTE-10\% threshold to evaluate where field or laboratory studies are feasible and as a reference for comparison to the results of those studies.

\subsection{Results}

Simulation results showed that the proportion of individuals passing multiple turbines and the potential for impact varied widely among runs, among flow levels, and in response to transportation. The maximum level of MTE reduced the number of spring Chinook salmon and steelhead by $10 \%$ only in scenarios with the transportation system turned off. Fall Chinook salmon were reduced by $10 \%$ in all scenarios with a maximum MTE except during a high-flow year with transportation. The levels of MTE required to reduce the number of migrants by $10 \%$ were relatively large.

\subsection{Multiple Turbine Effect}

Simulating a maximum MTE level identified fall Chinook salmon as the run at greatest risk from an MTE. Management actions such as spill and transportation were very effective at reducing turbine passage and thereby reducing the influence of MTE.

\subsubsection{Maximum Simulated Multiple Turbine Effect}

In simulations based on current management guidelines, only fall Chinook salmon survival was predicted to decrease by more than $10 \%$ when an MTE of $100 \%$ was imposed (Table 3.1). This result is consistent with the finding that a greater proportion of fall Chinook salmon pass multiple turbines than do other runs (Figure 3.1). These findings allow all but fall Chinook salmon to be screened out for further study of potential risk of MTE to the population. During high-flow conditions, fall Chinook salmon can be screened out as having a negligible potential for an effect at the population level.

Table 3.1. Relative Performance with Multiple Turbine Effect Set to $100 \%$

\begin{tabular}{||c|c|c|c|c||}
\hline \hline Transportation & Flow Year & Steelhead & Spring Chinook & Fall Chinook \\
\hline \hline \multirow{3}{*}{ On } & Low & $3 \%$ & $3 \%$ & $\mathbf{1 4 \%}{ }^{\text {(a) }}$ \\
\cline { 2 - 5 } & Average & $2 \%$ & $4 \%$ & $\mathbf{1 7 \%}$ \\
\cline { 2 - 5 } & High & $3 \%$ & $6 \%$ & $8 \%$ \\
\hline \multirow{3}{*}{ Off } & Low & $\mathbf{2 5 \%}$ & $\mathbf{5 0 \%}$ & $\mathbf{8 0 \%}$ \\
\cline { 2 - 5 } & Average & $3 \%$ & $7 \%$ & $\mathbf{6 5 \%}$ \\
\cline { 2 - 5 } & High & $7 \%$ & $\mathbf{1 6 \%}$ & $\mathbf{6 5 \%}$ \\
\cline { 2 - 5 } & (a) Values in bold exceed $10 \%$. &
\end{tabular}


When transportation was dropped from simulations without further adjustments to compensate for the change, turbine passage increased; MTE had a much greater effect on all populations during low-flow conditions and fall Chinook salmon under all flow levels (Table 3.1). Table 3.2 shows the percentages of individuals that passed multiple turbines for each scenario of run, flow year and transport. These findings illustrate that fall Chinook salmon management relies heavily on the juvenile fish transportation program at all flow levels. In contrast, spring Chinook salmon and steelhead relied heavily on transportation during low-flow years and somewhat during high flows when a greater proportion of water was passing the powerhouses. These results also support further analysis of fall Chinook salmon as the best test of the potential for MTEs.

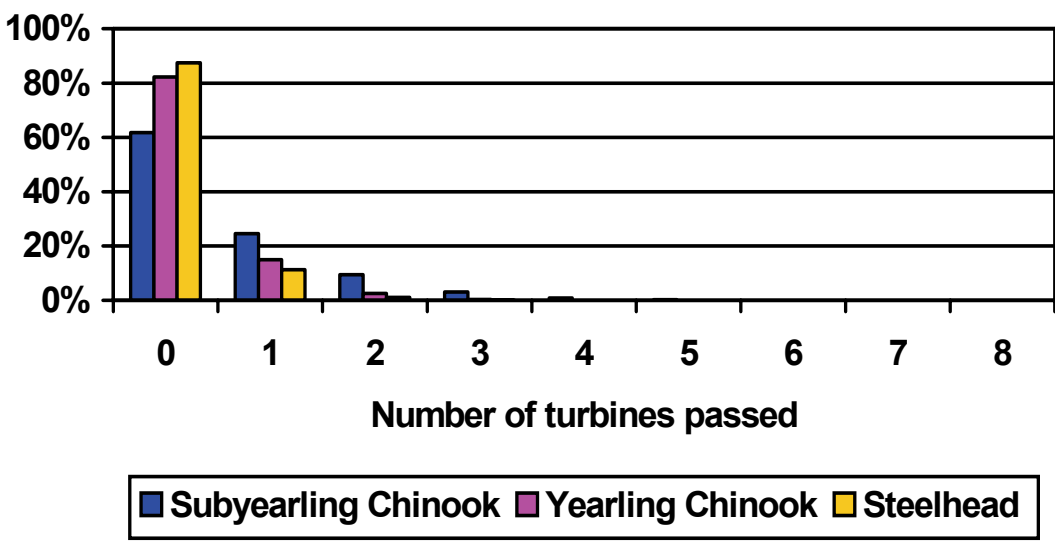

Figure 3.1. Proportion of Fish Passing Multiple Turbines in an Average Flow Year

Table 3.2. Percentage of Fish Passing One or More Turbines by Run, Flow Year, and Transport

\begin{tabular}{|c|c|c|c|c|c|c|c|c|c|}
\hline & & & \multicolumn{7}{|c|}{ Number of Turbines Passed } \\
\hline Run & Flow & Transport & 0 & 1 & 2 & 3 & 4 & 5 & 6 \\
\hline \multirow{6}{*}{$\begin{array}{l}\text { Spring } \\
\text { Chinook }\end{array}$} & \multirow[t]{2}{*}{ Low } & "On & 80 & 17 & $\overline{2}$ & $\overline{11}$ & $\overline{0}$ & 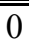 & $\overline{0} 0$ \\
\hline & & Off & 15 & 35 & 31 & 14 & 4 & 1 & 0 \\
\hline & \multirow[t]{2}{*}{ Average } & On & 82 & 15 & 2 & 0 & 0 & 0 & 0 \\
\hline & & Off & 62 & 31 & 7 & 1 & 0 & 0 & 0 \\
\hline & \multirow[t]{2}{*}{ High } & On & 80 & 15 & 4 & 1 & 0 & 0 & 0 \\
\hline & & Off & 45 & 39 & 13 & 2 & 0 & 0 & 0 \\
\hline \multirow[t]{6}{*}{ Steelhead } & \multirow[t]{2}{*}{ Low } & On & 85 & 13 & 2 & 0 & 0 & 0 & 0 \\
\hline & & Off & 35 & 40 & 19 & 5 & 1 & 0 & 0 \\
\hline & \multirow[t]{2}{*}{ Average } & On & 87 & 11 & 1 & 0 & 0 & 0 & 0 \\
\hline & & Off & 75 & 22 & 3 & 0 & 0 & 0 & 0 \\
\hline & \multirow[t]{2}{*}{ High } & On & 85 & 13 & 2 & 0 & 0 & 0 & 0 \\
\hline & & Off & 60 & 32 & 7 & 1 & 0 & 0 & 0 \\
\hline \multirow[t]{6}{*}{ Fall Chinook } & \multirow[t]{2}{*}{ Low } & On & 66 & 22 & 8 & 3 & 0 & 0 & 0 \\
\hline & & Off & 4 & 16 & 29 & 28 & 16 & 5 & 1 \\
\hline & \multirow[t]{2}{*}{ Average } & On & 62 & 25 & 9 & 3 & 1 & 0 & 0 \\
\hline & & Off & 8 & 27 & 34 & 22 & 7 & 1 & 0 \\
\hline & \multirow[t]{2}{*}{ High } & On & 73 & 20 & 6 & 1 & 0 & 0 & 0 \\
\hline & & Off & 8 & 27 & 34 & 22 & 8 & 1 & 0 \\
\hline
\end{tabular}




\subsubsection{What Level of Multiple Turbine Effect Is High Enough to Affect a Population?}

Having established that fall Chinook salmon were the most susceptible to a potential effect of passing multiple turbines, we then quantified what level of MTE would result in a $10 \%$ impact to the population. As simulated MTE increased from $0 \%$ to $100 \%$, relative predicted survivals decreased to as little as $86 \%$ during a low-flow year or as little as $20 \%$ during a low-flow year without transportation (Figure 3.2). By varying MTE in simulations, it was possible to determine that under normal management conditions in a low-flow year, an MTE of 59\% was required to reduce survival by 10\% (Table 3.3). With transport turned off, an MTE of only $6.5 \%$ resulted in a 10\% decrease in survival. In an average flow year, an MTE of $44.5 \%$ was required to reduce predicted survival by $10 \%$ with transportation, whereas an MTE of $10 \%$ was required without transportation. In a high-flow year, even an MTE of $100 \%$ did not reduce predicted survival by $10 \%$. However, in the absence of transportation, an MTE of only $10 \%$ was required to reduce survival by $10 \%$.

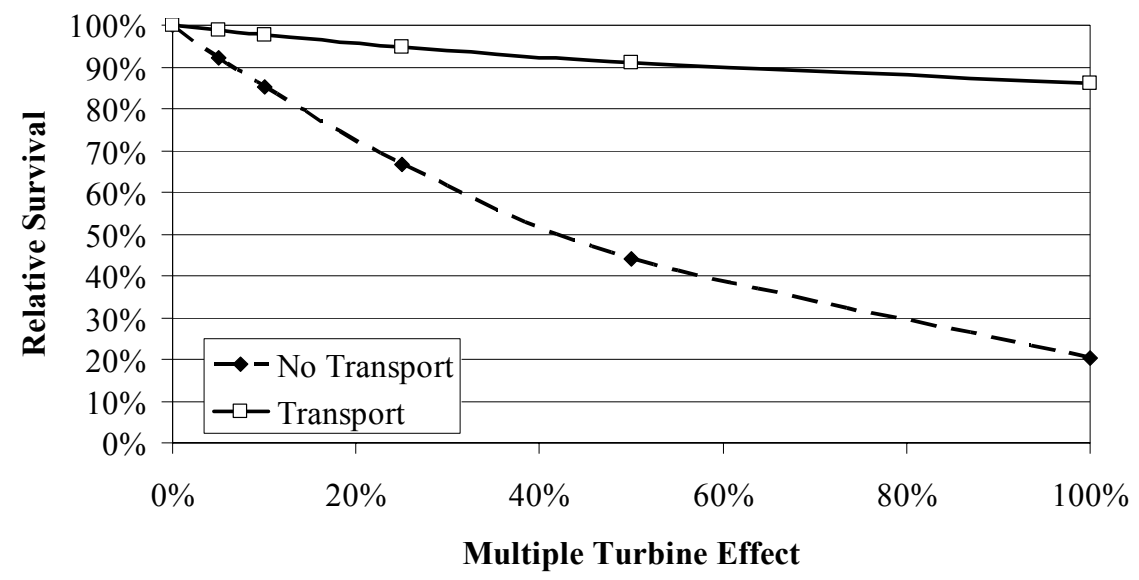

Figure 3.2. Relative Survivals for Fall Chinook Salmon Versus Simulated Multiple Turbine Effect with and Without Transport During a Low-Flow Year

Table 3.3. Multiple Turbine Effect Level at Which System Survival Is Decreased by 10\%

\begin{tabular}{||l|c|c||}
\hline \multicolumn{1}{|c|}{ Flow Year } & Transport & No Transport \\
\hline \hline Low & $59.0 \%$ & $6.5 \%$ \\
\hline Average & $44.5 \%$ & $10.0 \%$ \\
\hline High & NA $(>100 \%)$ & $10.0 \%$ \\
\hline
\end{tabular}

\subsection{Fish Passage Routing}

When MTE is simulated at its maximum, the proportion of fish that pass multiple turbines determines whether or not the number of migrants is reduced by more than $10 \%$. That proportion differed among scenarios due to the differences among runs, flow level, and transport. 


\subsubsection{Differences Among Runs}

The bulk of juvenile fall Chinook salmon migrate during the summer season, when flows are generally lower than in spring. Spill has not been favored in the summer because of concerns that fish migrating in the river may be exposed to near-lethal high temperatures and an increased risk of predation. Fall Chinook salmon juveniles also travel lower in the water column as they approach dams and are not guided away from turbine passage by fish guidance screens in the same proportion as are spring Chinook salmon or steelhead. To address those concerns while reducing the proportion of these fish that pass turbines to a level closer to that of spring Chinook salmon or steelhead, operational guidelines maximize transportation by curtailing spill and barging all fish collected in bypass systems. The result of those actions is that only slightly more fall Chinook salmon pass through turbines than do spring Chinook salmon or steelhead (Figure 3.1).

\subsubsection{Flow Year Effects}

Low flows (i.e., $<70 \mathrm{kcfs}$ in the Snake River) trigger changes in the operation of the hydrosystem. The most important change during the low-flow year chosen for simulation was a decision to operate projects that have the option to transport in a way that maximizes fish collection and minimizes exposure to other factors potentially affecting juvenile migrants, such as high temperatures or predation. Little or no water was allowed to flow through the spillways, increasing the efficiency of collection and transportation of juvenile migrants. High flows did not trigger a similar change in basic operational guidelines relative to average flows, but operational limits resulting from things such as powerhouse capacity or gas saturation regulations sometimes led to unexpected results. For example, the proportion of fish passing turbines sometimes increased as flows increased from average to high, due to the limits placed on spill to avoid excess dissolved gas.

\subsubsection{Transportation}

The Juvenile Fish Transportation Program reduced the proportion of fish encountering turbines, and its effects were apparent in the simulation results. Figure 3.1 shows that most simulated steelhead surviving past Bonneville Dam during an average flow year arrived there via the transport system. Migrants suffer some mortality during each segment of the downstream migration, and many of the surviving migrants are collected for transport at upstream dams. By the time fish reached Bonneville Dam, the majority of survivors were in the transport system. Maximum transport operations during low-flow conditions would leave few fish to migrate in the river. Transportation improves system survival and adult returns in most cases, although delayed mortality effects from transportation have not yet been fully quantified (Budy et al. 2002; Anderson et al. 2005a,b; Ham et al. 2005). Turning off the transport system in simulations revealed how much reliance is placed on the transportation system to reduce the proportion of fish passing turbines for each run and flow level. 


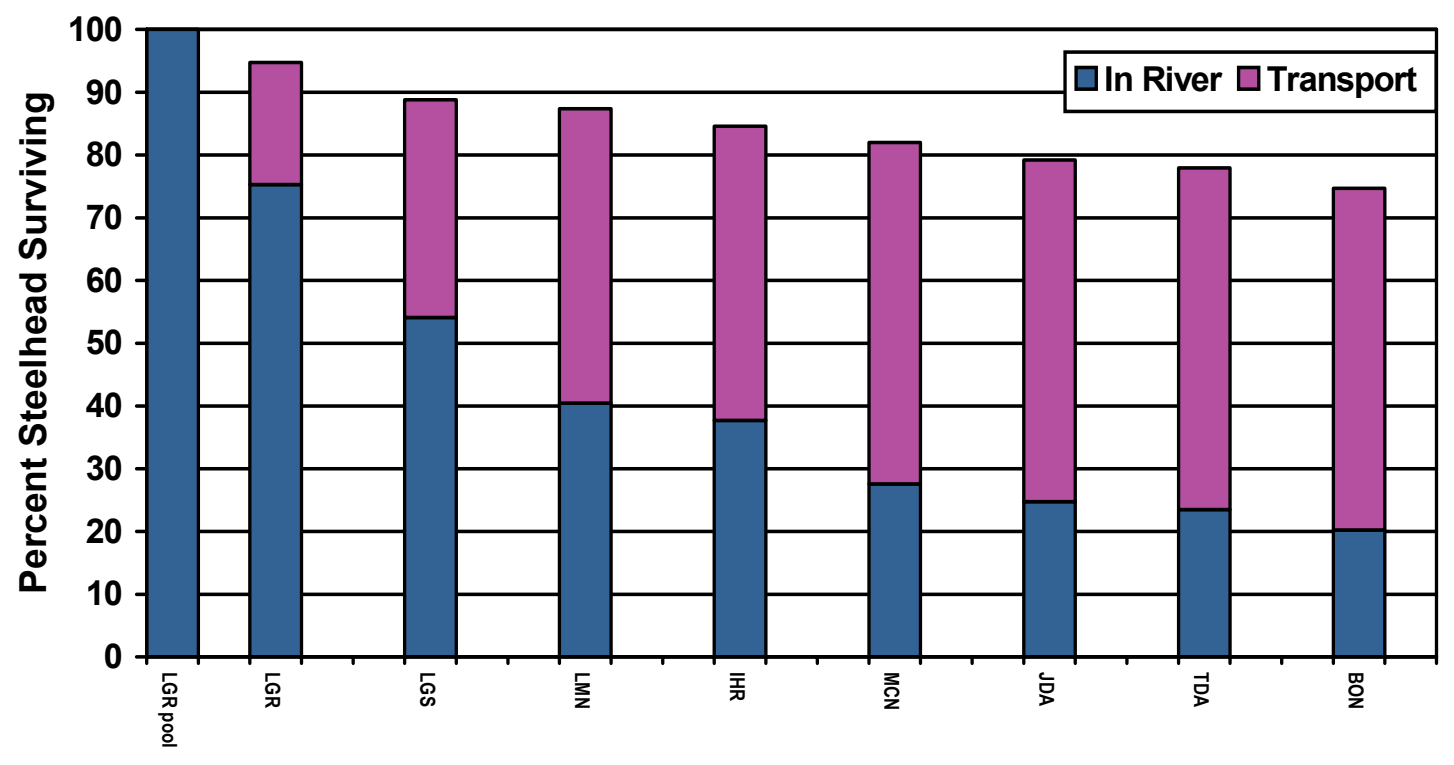

Downstream >

Figure 3.3. Percentage of Steelhead Entering Lower Granite Pool Surviving at Each Hydropower Project in the River and in the Transport System Under Average Flows

\subsection{Discussion}

Simulations revealed that current operational guidelines for the hydrosystem of the lower Snake and Columbia Rivers greatly reduced the proportion of fish that pass one or more turbines during their passage-route history. The potential for a $10 \%$ decline in the number of migrants due to an MTE was possible only for fall Chinook salmon.

\subsection{Key Results}

Of the thousands of combinations of passage routes possible for fish migrating from the upper Snake River toward the ocean, approximately $83 \%$ include more than one turbine passage. That number suggests that a large proportion of fish are likely to pass multiple turbines. If that were the case, the potential for an MTE to influence a run would be large. However, simulation results predict that spill and transportation protocols will be very successful at minimizing turbine passage in general and, therefore, the proportion of fish passing multiple turbines. The potential for an impact from MTE was limited to fall Chinook salmon that were not as easily guided away from turbine passage.

\subsubsection{Managing the System to Reduce Turbine Passage}

Our simulation results indicated that management actions are very effective at reducing turbine passage. If all management actions directed toward passing fish through non-turbine routes were canceled, the river might then be operated with little or no spill until flows exceeded the capacity of the powerhouse at a dam. That would result in essentially all fish passing turbines at each project and encountering multiple turbines along their passage-route history. Low-flow conditions without 
transportation approached that scenario, although fish guidance screens were not removed. Simulations without transportation turned off revealed that the current configuration and operational guidance for the Snake and Columbia river hydrosystem greatly reduced the proportion of fish passing turbines, relative to a hypothetical "no management action" scenario. Examples of specific management actions employed to reduce the proportion of fish that pass one or more turbines included fish guidance screens, spill, and the juvenile fish transportation program. In scenarios where those actions were in effect, it was common for individuals to pass fewer than two turbines during the downstream migration.

In scenarios with less than $10 \%$ of fish passing multiple turbines, there was no potential for MTE to reduce survival by $10 \%$ or more. Figure 4.1 is an example showing that the proportion of steelhead surviving downstream of Bonneville Dam was reduced from $74.7 \%$ with no MTE effect to $73.8 \%$ with a simulated MTE of $100 \%$ loss on passing a second turbine in an average flow year with transportation-a change of less than $2 \%$. Further investigation would be required to identify scenarios where maximum MTE reduced survival by at least $10 \%$.

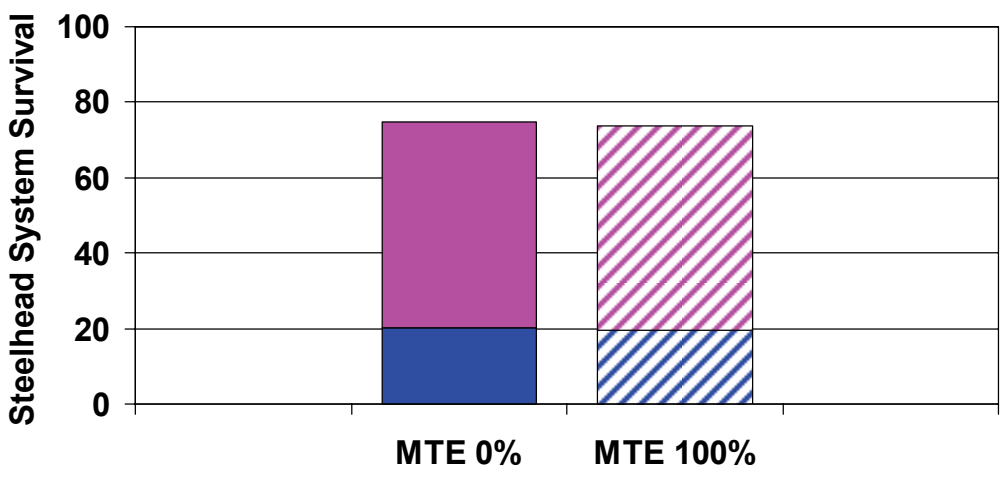

$\square$ In River $\square$ Transport $\square$ In River(100\%) $\square$ Transport(100\%)

Figure 4.1. System Survivals of Steelhead with or Without a Multiple Turbine Effect in an Average Flow Year with Transportation

The greatest influence of low flows on risk was related to changes in the operational guidelines. Maximizing transportation greatly reduced the number of fish exposed to turbines. Average summer flows (approximately $50 \mathrm{kcfs}$ in the Snake River) are low enough to trigger maximum transportation, but fall Chinook salmon approach dams lower in the water column and are less efficiently guided into juvenile bypass systems. Therefore, turbine passage remained higher than for other runs, and the potential for an effect was examined further by determining what threshold level of MTE would result in a $10 \%$ decrease in survival.

Turning off transportation in our simulations demonstrated how much reliance was placed on that program for each combination of run and flow level. Turbine passage was greatly increased when transportation was turned off, leading to a much greater potential for MTE to decrease the number of migrants by $10 \%$ or more. In actual practice, a decision to curtail transportation would be accompanied by adjustment of other system operations to compensate for this change. These adjustments would at least partially offset the increase in turbine passage, and the potential for an MTE would be less than for the present simulations without transportation. 


\subsection{Implications}

In simulations with current management guidelines imposed for fall Chinook salmon, an MTE of at least $44.5 \%$ was required to decrease the number of migrants surviving downstream of Bonneville Dam by $10 \%$, relative to the same operations in the absence of an MTE. An MTE of that magnitude would overshadow normal turbine mortality of around 10\% (Iwamoto et al. 1994; Muir et al. 1996; Ferguson et al. 2004). If an MTE of $44.5 \%$ were combined a base mortality rate of approximately $10 \%$, the combined mortality rate would approach $50 \%$ for fish passing a second turbine. Whether such a value is realistic could be the subject of future tests. The high magnitude of the value means that it might be possible to do an experiment or collect evidence to support or refute the existence of an effect in the field. In fact, the necessary information may already have been collected but would need to be analyzed for this purpose. This possibility is explored in the following section.

\subsection{Verification of an Effect with Field Data}

Low-flow years provide an opportunity to analyze data from passive integrated transponder (PIT) tags with more certainty about the passage-route histories used by juvenile salmon. For example, if spill does not occur, the possible passage-route combinations decrease from more than 4000 to something less than 300. Another critical benefit is that at many hydropower projects, only two routes remain in the absence of spill, one of which is instrumented to detect PIT tags. Rather than having to guess whether undetected individuals passed through spill or turbines, researchers can assign the fish to turbine passage if they are not detected within the juvenile bypass system. Tagged fish would also be much more likely to encounter turbines in the absence of spill. If an MTE of $44.5 \%$ occurred in 2001, a low-flow year with almost no spill, it should be possible to detect it by examining downstream detection probabilities or adult returns of PIT-tagged fish. Conversely, if an MTE was not detected, it might be possible to establish what level of MTE would have been detectable in a statistical sense. If such a bound can be established, it would be possible to assume that MTE is less than the minimum detectable level and that might eliminate MTE as an important risk to some or all populations of migrating juvenile salmonids. If the potential for an MTE cannot be eliminated, then a designed experiment may be needed to establish its magnitude and the risk to the population.

\subsection{Conclusions}

The potential for a multiple turbine effect to have adverse impacts on populations of spring Chinook salmon and steelhead is negligible under current management guidelines that use spill and the transportation system to minimize turbine passage. However, in spite of the management efforts to minimize turbine passage during the summer migration period, the potential for an impact to fall Chinook salmon cannot yet be ruled out.

The high level of MTE required to decrease the number of migrants by $10 \%$ under current management guidelines for fall Chinook salmon is amenable to testing with field data. Based on our results, it will be possible to design an experiment with sufficient power to detect a significant impact upon the number of migrating juveniles. 


\subsection{References}

Anderson JJ, RA Hinrichsen, C Van Holmes, and KD Ham. 2005a. Historical Analysis of PIT Tag Data for Transportation of Fish at Lower Granite, Little Goose, Lower Monumental and McNary Dams: Task 1: Analysis of In-River Environmental Conditions. PNWD-3514, Battelle-Pacific Northwest Division, Richland, Washington.

Anderson JJ, RA Hinrichsen, C Van Holmes, and KD Ham. 2005b. Historical Analysis of PIT Tag Data for Transportation of Fish at Lower Granite, Little Goose, Lower Monumental and McNary Dams: Task 2: Analysis of Near Shore Oceanic and Estuarine Environmental Conditions. PNWD-3522, Battelle-Pacific Northwest Division, Richland, Washington.

Becker JM, CS Abernethy, and DD Dauble. 2003. "Identifying the effects on fish of changes in water pressure during turbine passage." Hydro Review 22(5):32-42.

Budy P, GP Thiede, N Bouwes, CE Petrosky, and H Schaller. 2002. "Evidence linking delayed mortality of Snake River salmon to their earlier hydrosystem experience." North American Journal of Fisheries Management 22(1):35-51.

Čada GF. 2001. "The development of advanced hydroelectric turbines to improve fish passage survival." Fisheries 26(9):14-23.

Coutant CC and RR Whitney. 2000. "Fish behavior in relation to passage through hydropower turbines: A review." Transactions of the American Fisheries Society 129:351-380.

Deng Z, GR Guensch, CA McKinstry, RP Mueller, DD Dauble, and MC Richmond. 2005. "Evaluation of Fish-Injury Mechanisms During Exposure to Turbulent Shear Flow." Canadian Journal of Fisheries and Aquatic Sciences 62(7):1513-1522.

Ferguson JW, GM Matthews, RL McComas, RF Absolon, DA Brege, MH Gessel, and LG Gilbreath. 2004. Passage of Adult and Juvenile Salmon Through Federal Columbia River Power System Dams. Technical Memorandum, NOAA Fisheries, Northwest Fisheries Science Center, Seattle, Washington.

Groves AB. 1972. Effects of hydraulic shearing actions on juvenile salmon. Northwest Fisheries Science Center, Seattle, Washington.

Ham KD, RA Hinrichsen, C Van Holmes, and JJ Anderson. 2005. Historical Analysis of PIT Tag Data for Transportation of Fish at Lower Granite, Little Goose, Lower Monumental and McNary Dams: Task 3: Analysis of Hatchery Effects. PNWD-3528, Battelle-Pacific Northwest Division, Richland, Washington. 
Iwamoto R N, WD Muir, BP Sandford, KW McIntyre, DA Frost, JG Williams, SG Smith, and JR Skalski. 1994. Survival estimates for the passage of juvenile Chinook salmon through the Snake River dams and reservoirs, 1993. Report to Bonneville Power Administration, Portland, Contract DE-AI7993BP10891, 126 p. plus appendices. (Available from Northwest Fisheries Science Center, 2725 Montlake Blvd. E., Seattle, WA 98112-2097.)

Mesa GM. 1994. "Effects of multiple acute stressors on the predator avoidance ability and physiology of juvenile Chinook salmon." Transactions of the American Fisheries Society 123:786-793.

Muir JF. 1959. "Passage of young fish through turbines." Journal of the Power Division Proceedings of the American Society of Civil Engineers. PO1:23-46.

Muir WD, SG Smith, EE Hockersmith, SF Achord, RF Absolon, PA Ocker, MB Eppard, TE Ruehle, JG Williams, RE Iwamoto, and JR Skalski. 1996. Survival estimates for the passage of yearling Chinook salmon and steelhead through Snake River dams and reservoirs, 1995. Portland, Oregon: U.S. Department of Energy, Bonneville Power Administration, Division of Fish and Wildlife.

NMFS. 2000. Biological Opinion: Reinitiation of Consultation on Operation of the Federal Columbia River Power System, including the juvenile fish transportation program and 19 Bureau of Reclamation Projects in the Columbia Basin. National Marine Fisheries Service, Northwest Region, Portland, Oregon. December 21.

Neitzel DA, DD Dauble, GF Čada, MC Richmond, GR Guensch, RP Mueller, CS Abernethy, and B. Amidan. 2004. "Survival Estimates for Juvenile Fish Subjected to a Laboratory-Generated Shear Environment." Transactions of the American Fisheries Society 133:447-454.

Schoeneman DE and CO Junge, Jr. 1954. "Investigations of mortalities to downstream migrant salmon at two dams on the Elwha River." Research Bulletin \#3, Washington State Department of Fisheries, Olympia, Washington.

Schoeneman DE, RT Pressey, and CO Junge, Jr. 1961. "Mortalities of downstream migrant salmon at McNary Dam." Transactions of the American Fisheries Society 90(1):58-72.

USACE. 2005. Fish Passage Plan: Corps of Engineers Projects. U.S. Army Corps of Engineers, Northwestern Division, Portland, Oregon.

Whitney RR, LD Calvin, MW Erho Jr., and CC Coutant. 1997. Downstream passage for salmon at hydroelectric projects in the Columbia River Basin: Development, installation, and evaluation. Report 97-15, Northwest Power Planning Council, Portland, Oregon.

Williams JG and GM Matthews. 1995. "A review of flow and survival relationships for spring and summer Chinook salmon, Oncorhynchus tshawytscha, from the Snake River Basin." Fishery Bulletin 93:732-740. 